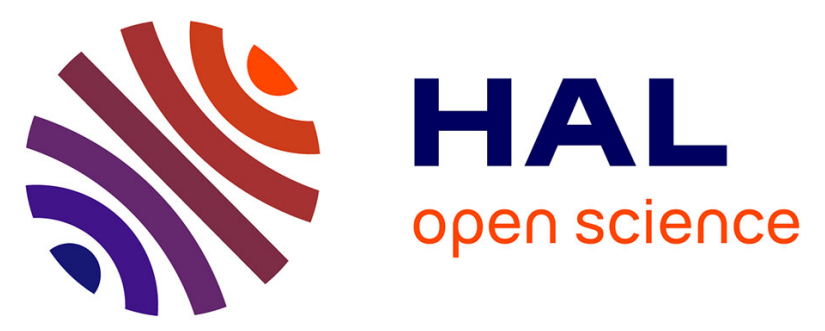

\title{
An Environmental Burden Shifting Approach to Re-evaluate the Environmental Impacts of Products
}

Xi Yu, Antoine Nongaillard, Aicha Sekhari, Abdelaziz Bouras

\section{To cite this version:}

Xi Yu, Antoine Nongaillard, Aicha Sekhari, Abdelaziz Bouras. An Environmental Burden Shifting Approach to Re-evaluate the Environmental Impacts of Products. 12th IFIP International Conference on Product Lifecycle Management (PLM 2015), Oct 2015, Doha, Qatar. pp.56-65, 10.1007/978-3319-33111-9_6. hal-01377428

\section{HAL Id: hal-01377428 \\ https://hal.inria.fr/hal-01377428}

Submitted on 7 Oct 2016

HAL is a multi-disciplinary open access archive for the deposit and dissemination of scientific research documents, whether they are published or not. The documents may come from teaching and research institutions in France or abroad, or from public or private research centers.
L'archive ouverte pluridisciplinaire HAL, est destinée au dépôt et à la diffusion de documents scientifiques de niveau recherche, publiés ou non, émanant des établissements d'enseignement et de recherche français ou étrangers, des laboratoires publics ou privés.

\section{(c)(1)}

Distributed under a Creative Commons Attribution| 4.0 International License 


\title{
An environmental burden shifting approach to re-evaluate the environmental impacts of products
}

\author{
Xi YU ${ }^{1,2}$, Antoine NONGAILLARD ${ }^{3}$, Aicha SEKHARI ${ }^{2}$, Abdelaziz BOURAS $^{4}$ \\ ${ }^{1}$ Chengdu University, School of Computer Science, China oliveryx@163.com \\ ${ }^{2}$ University Lyon 2 Lumière, DISP laboratory, France aicha.sekhari@univ-lyon2.fr \\ ${ }^{3}$ Université de Lille 1,IUT'A - Dépt. Informatique, France antoine.nongaillard@ univ-lille1.fr \\ ${ }^{4}$ Qatar University, Computer Science Department, Doha, Qatar abdelaziz.bouras@qu.edu.qa
}

\begin{abstract}
Life cycle assessment (LCA) can help enterprises evaluate their product's environmental impacts through the entire product life cycle (PLC). On the basis of the evaluation result, phases which need to take activities to reduce the environmental impacts can be found out. However, the activities taken in a phase may influence the environmental impacts in other phases, so the effect of the activities should be re-evaluated. Under the pressure from the market, enterprises need to assess the effect of these activities quickly. Nevertheless, re-evaluate by using conventional LCA is a time-consuming work. This paper proposes a novel approach to re-evaluate the environmental impacts of product based on LCA and Pareto rule which can reduce the time of assessment. A printed circuit board (PCB) case study is conducted using this approach. The outcome shows that the new approach can re-evaluate the environmental impacts more efficiently without influence the validity.
\end{abstract}

Keywords: Product Life Cycle; Printed Circuit Board; Life Cycle Assessment; Life Cycle Impact Assessment; Material Flow Analysis; Life Cycle Inventory; Pareto rule

\section{Introduction}

As any improvement activity taken in a phase may make the environmental impact reduce in a phase but increase in other phases. This so called environmental burden shifting phenomenon forces analysts to collect all the related data in every time when assess the activities' environmental effects. Then the re-evaluation is similar as evaluate again and still time-consuming. In order to make the re-evaluation more efficient and without influence the validity of the result, this paper proposes a novel approach based on LCA method to re-evaluate environmental impacts after some improvement activities taken. The Pareto rule is used to make the re-evaluation only focus on the materials which have most significant contribution to the special environmental impact. A graph-based model is proposed to make the environmental burden shifting analysis more intuitive and comprehensive. On the basis of the data collected at the first time before activities taken and the data after activities taken, the variation of the concerned materials between two times can be calculated. By checking databases or measure on site, the emission factors of each material in each 
phase can be acquired. Multiple the value of variations with the value of emission factors and then add the original environmental emissions, the new environmental emissions of these materials can be calculated out.

This paper is organized as follows: Section (2) describes the related works. Section (3) focuses on the main proposed model and approach. A case study is provided in Section (4) to illustrate the approach. Finally, some conclusions are presented.

\section{Literature review}

Many methods have been proposed to evaluate the environmental impacts of products. Such as the Ten golden Rules (Luttropp and Lagerstedt 2006), MET-matrix (Materials, Energy, Toxic emissions) (Knight and Jenkins 2009) in terms of qualitative; the Environmentally Responsible Product/Process assessment matrix (ERPA)(Graedel et al. 1996), Environmental Product Life Cycle Matrix (EPLC)(Gertsakis et al. 1997), Product Investigation, Learning and Optimization Tool (PILOT)(Wimmer et al. 2004), in terms of semi-qualitative; The LCA (ISO14040 2006), material flow analysis (MFA) in terms of quantitative. As the qualitative and semi-qualitative methods cannot provide precise result of environmental impacts of product to satisfy the enterprises' requirements, this research focuses on the quantitative study and the literatures related with LCA.

LCA is more accepted in industry because it can assess product's EIs associated with all the phases of the product's life from cradle-to-grave (Rebitzer et al. 2004). The importance of different life cycle phases and environmental releases can be evaluated by LCA (eHertwich and Hammitt 2001). The ISO 14040 standard defines the main stages of LCA as shown in Figure 1 (ISO14040 2006).

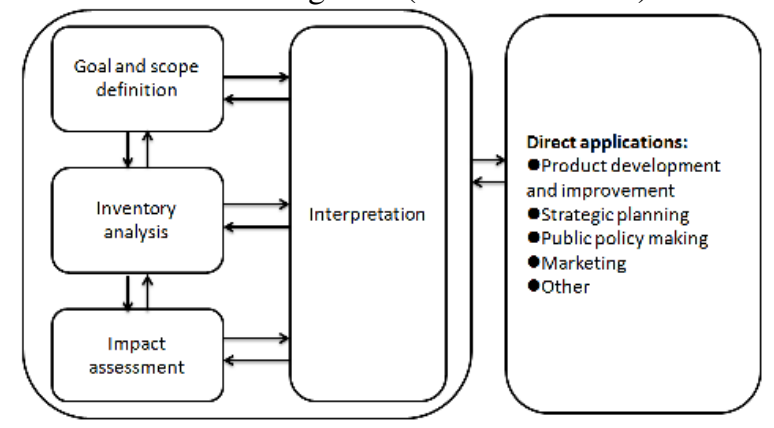

Figure 1 Stages of an LCA

MFA is an excellent tool to analyze material flows and stocks, it is can also used to evaluate the results of analysis and control material flows in view of certain goals such as sustainable development (Hendriks et al. 2000). It can be divided into two basic types of material flow-related analyses as shown in

Table 1 (Bringezu and Moriguchi 2002). The type I can be called as substance flow analysis (SFA), the result of it can be applied to control the flow of hazardous substances. The procedure of MFA usually comprises four steps: goal and systems definition, process chain analysis, accounting and balancing, modeling and 
evaluation. The systems definition illustrate the formulation of the target questions, the scope and systems boundary. The process chain analysis defines the processes for which the inputs and outputs are to be determined quantitatively by accounting and balancing. The fundamental principle of mass conservation is used in this step. Modeling may be applied in the basic form of "bookkeeping". The evaluation of results is related to the primary interest and basic assumptions.

Table 1 Types of material flow-related analysis

\begin{tabular}{|c|c|c|c|}
\hline \multirow{2}{*}{$\begin{array}{l}\text { Type of } \\
\text { analysis }\end{array}$} & \multicolumn{3}{|c|}{$\mathrm{I}$} \\
\hline & a & $\mathrm{b}$ & $\mathrm{c}$ \\
\hline \multirow{8}{*}{$\begin{array}{l}\text { Objects of } \\
\text { primary } \\
\text { interest }\end{array}$} & \multicolumn{3}{|c|}{ Specific environmental problems related to certain impacts per unit flow of: } \\
\hline & $\begin{array}{l}\text { Substances } \\
\text { e.g. } \mathrm{Cd}, \mathrm{Cl}, \mathrm{Pb}, \mathrm{Zn} \text {, } \\
\mathrm{Hg}, \mathrm{N}, \mathrm{P}, \mathrm{C}, \mathrm{CO}_{2} \text {, } \\
\mathrm{CFC}\end{array}$ & $\begin{array}{l}\text { materials } \\
\text { e.g. wooden products, energy } \\
\text { carriers, excavation, biomass, } \\
\text { plastics }\end{array}$ & $\begin{array}{l}\text { products } \\
\text { e.g. diapers, batteries, } \\
\text { cars }\end{array}$ \\
\hline & \multicolumn{3}{|c|}{ within certain firms, sectors, regions } \\
\hline & \multicolumn{3}{|c|}{ II } \\
\hline & $\mathrm{a}$ & \begin{tabular}{|c|c|}
$\mathrm{b}$ & \\
\end{tabular} & $\mathrm{c}$ \\
\hline & \multicolumn{3}{|c|}{ Problems of environmental concern related to the throughput of: } \\
\hline & $\begin{array}{l}\text { firms } \\
\text { e.g. single plants, } \\
\text { medium and large } \\
\text { companies }\end{array}$ & $\begin{array}{l}\text { sectors } \\
\text { e.g. production sectors, } \\
\text { chemical industry, } \\
\text { construction }\end{array}$ & $\begin{array}{l}\text { regions } \\
\text { e.g. total or main } \\
\text { throughput, mass } \\
\text { flow balance, total } \\
\text { material requirement }\end{array}$ \\
\hline & \multicolumn{3}{|c|}{ associated with substances, materials, products } \\
\hline
\end{tabular}

The LCA and MFA can both support enterprises reduce EIs of products from the review of existing works. LCA can find out the main issues through the entire PLC, while it is not suitable for a quick re-evaluation because it is a time-consuming method. MFA can find out the main material flows or stocks which can bring severe EIs, yet it cannot illustrate the EIs of product directly.

\section{Graph-based Model considering environmental burden shifting}

The traditional LCA can provide useful information either to identify which phases of the product lifecycle have significant environmental impacts or to compare the environmental performance of two alternatives. Both of these objectives require the collection of massive amount of data from different enterprises involved in the whole product life cycle. (Loijos 2013) points out that at least 70 hours are needed to collect primary data in traditional LCA. Even for some simplified LCA methods, 1-20 person-days of work are required (Hochschorner and Finnveden 2003). The time-consuming data collection is a big issue for enterprises to re-evaluate the environmental performance of a product. Any change at a specific phase may influence the environmental impacts of other lifecycle phases due to the burden shifting phenomenon. Moreover, a totally new data collection is required to re-evaluate the environmental performance of the updated product lifecycle. 
Some researchers claim to consider the environmental burden shifting problem (Suyang and Liu 2010; Yang et al. 2012; Kanth et al. 2011). However, this phenomenon has been avoided thanks to the re-collection of all environmental data after each change. In this section, a graph-based model is proposed to truly consider the burden shifting phenomenon, which leads to a new evaluation model of the environmental performance for product lifecycle. An activity impacts directly the amount of materials/energies used in a phase and impacts indirectly other lifecycle phases. On the basis of the variation of the mass of materials or energy used in a phase after an activity occurred, the new environmental release can be computed thanks to a simple reverse engineering. The reverse engineering using in this paper refers to the environmental release of a material or energy can be calculated by multiple the mass of the material or energy with the emission factor (Eilam 2011; EPA 1995). Finally, the environmental impacts of each phase can be calculated and aggregated to determine the environmental performance of the whole product lifecycle.

Before describing the new model, some definitions are required. An "Activity" corresponds to the changes made by the user in order to reduce the environmental impacts. Activity can be described in terms of 5W1H (WHEN, WHERE, WHO, WHY, WHAT, and HOW) (Matsuyama et al. 2013), as shown in Table 2. For example, the upgrading process for a personal computer is defined in Table 3 (Suesada et al. 2007).

Table 2 Definition of $5 \mathrm{~W} 1 \mathrm{H}$ of a lifecycle activity

\begin{tabular}{cc}
\hline 5W1H & Definition \\
\hline WHEN & Name of an lifecycle activity \\
\hline WHERE & Location of an lifecycle activity \\
\hline WHO & Stakeholder, who treats a product or its components \\
\hline WHY & The application of the activity \\
\hline WHAT & A product or its components treated in an lifecycle activity \\
\hline HOW & Treatment means in an lifecycle activity \\
\hline
\end{tabular}

Table 3 Example of description of lifecycle activity

\begin{tabular}{llll}
\hline 5W & Content & 1 & Content \\
\cline { 1 - 2 } WHEN & Upgrading &
\end{tabular}

An "Impact" is the relationship between different phases due to an activity at a specific lifecycle phase. Impacts between lifecycle phases are illustrated by dotted lines in Figure 2. The variations of energy and materials are used to quantify the impact. The proposed model considers direct impacts between two lifecycle phases as well as indirect impacts, which correspond to the secondary impacts generated by the direct consequences of an activity. 


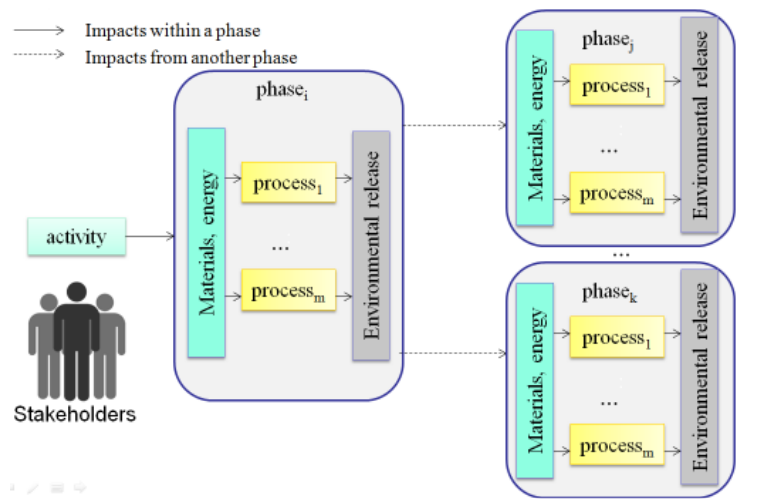

Figure 2 The characteristic of interaction among different lifecycle phases

Figure 3 illustrates the graph-based model, based on the scenario in Figure 2. Each node in the graph represents a lifecycle phase. Each phase is characterized by mass of materials and energy. $\delta_{i j}^{n}$ represents the variation of mass of materials and

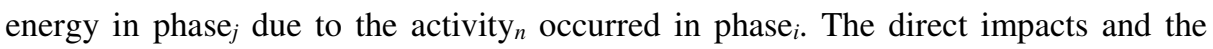
indirect impacts are respectively depicted by doted arrows and dashed arrows. Each impact $\delta$ has to be defined specifically between each pair of phases.

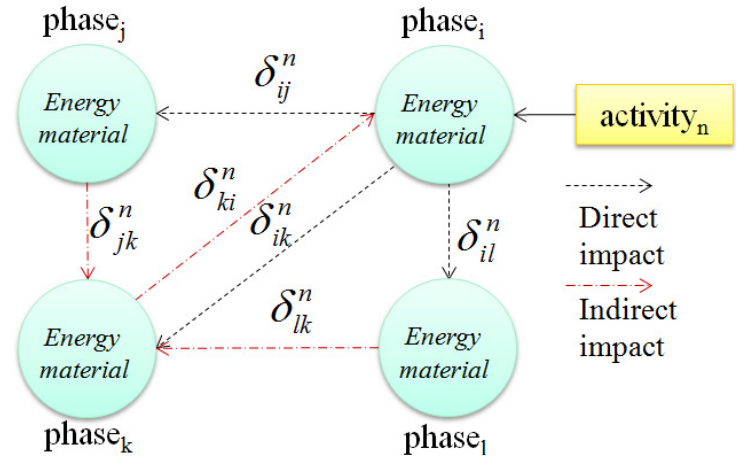

Figure 3 Graph-based model considering the environmental burden shifting caused by one activity

In practice, many activities may occur at same time, each activity may have impacts on a specific phase. Then the model can be depicted as Figure 4. As shown in Figure 4, the final variation of mass of materials and energy in phase ${ }_{j}$ is the sum of the variation of mass of materials and energy caused by different activities occurred in different phases. 


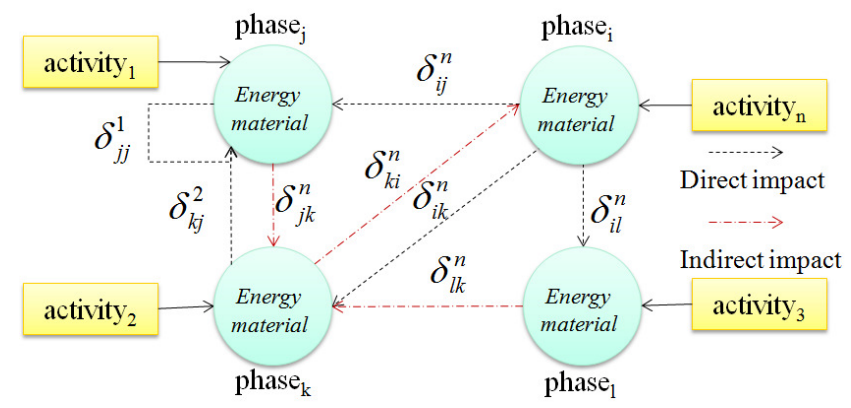

Figure 4 Graph-based model considering the environmental burden shifting caused by multi activities

The mass of materials or amount of energy used in different phases can be directly acquired by companies. The variation of material $k_{k}$ or energy used in the influenced phase $_{j}$ caused by activity ${ }_{n}$ can be calculated thanks to equations (1):

$$
\begin{aligned}
& \delta_{j M_{k}}^{n}=M_{j M_{k}}^{\prime}-M_{j M_{k}} \\
& \delta_{j E}^{n}=M_{j E}^{\prime}-M_{j E}
\end{aligned}
$$

$\delta_{j M_{k}}^{n}$ and $\delta_{j E}^{n}$ represent the mass of material $k_{k}$ and amount of energy changed by the activity $_{n}$ in the phase ${ }_{j}$ respectively. $M_{j M_{k}}^{\prime}$ and $M_{j E}^{\prime}$ denotes the mass of materials and amount of energy in the influenced phase ${ }_{j}$ after the activity is taken in a phase respectively. $M_{j M_{k}}$ and $M_{j E}$ represents the original mass of material $k$ and amount of energy consumed in the influenced phase $_{j}$ respectively.

An activity taken in a phase can make a material/energy change in different phases. Therefore, when calculate the variation of a material/energy in the specific phase, all the activities which have influence in the specific phase must be taken into account. The total variation of a material/energy in the specific phase corresponds to the accumulation of each variation due to different activities. It can be expressed by equations (2) and (3):

$$
\begin{gathered}
\delta_{j M_{k}}=\delta_{j M_{k}}^{1}+\delta_{j M_{k}}^{2} \ldots+\delta_{j M_{k}}^{n} \\
\delta_{j E}=\delta_{j E}^{1}+\delta_{j E}^{2} \ldots+\delta_{j E}^{n}
\end{gathered}
$$

$\delta_{j M_{k}} / \delta_{\mathrm{jE}}$ denotes the total variation of material ${ }_{k} /$ energy in the specific phase ${ }_{j}$.

From the existing databases or statistic data, each material/energy has its own environmental emission factor. Enterprises can estimate the environmental emission factor of each material/energy used in their own phase based on their process and statistic data. For example, $2.56 \mathrm{~kg}$ carbon dioxide is released by combustion $1 \mathrm{~kg}$ gasoline (International 2011). The value of the carbon dioxide emission is called the environmental emission factor of $1 \mathrm{~kg}$ gasoline. Then the variation environmental emission can be calculated by multiple the variation of material/energy used in the specific phase with the corresponding environmental emission factor as formula(4).

$$
\begin{aligned}
& e m \delta_{j M_{k}}=\delta_{j M_{k}} * \text { factor }_{j M_{k}} \\
& e m \delta_{j E}=\delta_{j E} * \text { factor }_{j E}
\end{aligned}
$$


The $e m \delta_{j M_{k}}$ and $e m \delta_{j E}$ denote the variation of environmental emission of material $k$ and energy in the specific phase respectively. The factor $_{j M_{k}}$ and factor $_{j E}$ denotes the environmental emission factor of the material $k$ and energy in the specific phase ${ }_{j}$ respectively.

Since the original environmental emission of materialk and energy in the influenced phasej is already existing, the new environmental emission of materialk and energy can then be acquired by adding the original value with the variation value as shown in equations (5).

$$
\begin{aligned}
& e m_{j M_{k}}^{\prime}=e m_{j M_{k}}+e m \delta_{j M_{k}} \\
& e m_{j E}^{\prime}=e m_{j E}+e m \delta_{j E}
\end{aligned}
$$

$e m_{j M_{k}}$ and $e m_{j E}$ represent the original environmental emission of materialk and energy consumed in the influenced phasej respectively. $e m_{j M_{k}}^{\prime}$ and ${ }^{e m_{j E}^{\prime}}$ represents the environmental emission of the materialk and energy consumed in the influenced phasej after activities are taken in several phases respectively.

Then the new environmental emission of the environmental impact category in the influenced phasej can be calculated by summing all materials and energy which belong to the special environmental impact category.

$$
e m_{j C_{i}}^{\prime}=\sum_{k=1}^{n} e m_{j M_{k}}^{\prime}+e m_{j E}^{\prime}
$$

The ${ }^{e m_{j c_{i}}^{\prime}}$ denotes the environmental emission of the special environmental impact categoryi in the influenced phasej after activities taken in other phases.

After the environmental emissions of each environmental impact category are calculated, users can choose different LCIA (Life Cycle Impact Assessment) methods to calculate the environmental impacts of the influenced phase.

In order to improve the efficiency of the environmental performance re-evaluation process, the time required to collect all data must be reduced, without affecting the validity of the results. The "Pareto principle" (also known as the 80-20 rule) provides a theoretical guide to achieve this objective. This rule states that only $20 \%$ of the time normally required to collect all data is sufficient to get $80 \%$ of these data (Halog and Manik 2011). This Pareto principle can be applied to environmental impact assessment problems. For example, even if a user is interested in the global warming issue of a product, he does not need to collect all the environmental data related with this issue. Indeed, since the global warming is mainly caused by the greenhouse gases (GHG) such as carbon dioxide (CO2), methane (CH4), and Nitrous Oxide (N2O), a user only needs to collect the data of materials and processes which have significant contributions to these GHG emissions. In the practice, the Pareto principle can be introduced in our model during environmental burden shifting analysis. 


\section{Conclusion:}

Enterprises take some environmental friendly activities in their own life cycle phase to improve the environmental performance of their product. However, through the entire product life cycle, any activities taken in a phase may bring some influences in other phases and make the environmental burden shift from one phase to other phases. Therefore, an approach is needed to evaluate the environmental effects of these activities. In the traditional LCA, the environmental burden shifting issues are dealt by re-collect all the related data every time in each phase. This make the traditional LCA becomes a time-consuming method. The approach proposed in this paper uses the Pareto rule to deal with the data collection issues. The time of data collection is decreased by only focuses on the most significant materials/energies which contribute the special environmental impact category. In order to make the environmental burden shifting analysis more intuitive and comprehensive, a graph-based model is proposed to help users analyze the interaction between different phases. On the basis of the existing data of input materials/energies before and after activities taken in some phases, the variation of these materials can be calculated. By multiple the environmental emission factors of these materials/energies in each phase, the new environmental emission in each phase is acquired. In the future, a case study will be conducted to test this new approach.

\section{Acknowledgements}

This project has been funded with support from the European Commission Project (EMA2-2010-2359) and Hubert Curien Partnership with Cai Yuanpei China program 2012-2014. This publication reflects the views only of the author, and the Commission cannot be held responsible for any use which may be made of the information contained therein.

\section{References}

1. Bringezu, S. and Y. Moriguchi. 2002. Material flow analysis. A handbook of industrial ecology, 79.

2. eHertwich, E. G. and J. K. Hammitt. 2001. A decision-analytic framework for impact assessment part I: LCA and decision analysis. The International Journal of Life Cycle Assessment, 6(1) 5-12.

3. Eilam, E. 2011. Reversing: secrets of reverse engineering, John Wiley \& Sons.

4. EPA. 1995. missions Factors \& AP 42, Compilation of Air Pollutant Emission Factors. U.S. Environmental protection agency. Retrieved 2.28, 2014, from http://www.epa.gov/ttn/chief/ap42/index.html.

5. Gertsakis, J., C. Ryan and H. Lewis. 1997. A guide to EcoReDesign: improving the environmental performance of manufactured products, Centre for Design, Royal Melbourne Institute of Technology.

6. Graedel, T. E., B. R. Allenby, A. Telephone and T. Company. 1996. Design for environment, Prentice Hall Upper Saddle River, NJ. 
7. Halog, A. and Y. Manik. 2011. Advancing integrated systems modelling framework for life cycle sustainability assessment. Sustainability, 3(2) 469-499.

8. Hendriks, C., R. Obernosterer, D. Müller, S. Kytzia, P. Baccini and P. H. Brunner. 2000. Material flow analysis: A tool to support environmental policy decision making. Case-studies on the city of Vienna and the Swiss lowlands. Local Environment, 5(3) 311-328.

9. Hochschorner, E. and G. Finnveden. 2003. Evaluation of two simplified life cycle assessment methods. The International Journal of Life Cycle Assessment, 8(3) $119-128$

10. International, P. 2011. LCA data bases. GaBi Software. Retrieved 14 Feb, 2014, from http://www.gabi-software.com.

11. ISO14040. 2006. Environmental management-life cycle assessment-principles and framework. Environmental Management. 3.

12. Kanth, R. K., P. Liljeberg, H. Tenhunen, Q. Wan and L. Zheng. 2011. Insight into quantitative environmental emission analysis of printed circuit board. Ed.^Eds. Environment and Electrical Engineering (EEEIC), 2011 10th International Conference on. IEEE.

13. Knight, P. and J. O. Jenkins. 2009. Adopting and applying eco-design techniques: a practitioners perspective. Journal of Cleaner Production, 17(5) 549-558.

14. Loijos, A. 2013. Making Primary Data Collection In LCA Faster And More Accurate. LinkCycle. $\quad$ Retrieved 13 Feb, 2014, from http://www.linkcycle.com/making-primary-data-collection-in-lca-faster-and-more-ac curate/.

15. Luttropp, C. and J. Lagerstedt. 2006. EcoDesign and The Ten Golden Rules: generic advice for merging environmental aspects into product development. Journal of Cleaner Production, 14(15) 1396-1408.

16. Matsuyama, Y., S. Fukushige and Y. Umeda. 2013. Proposal of a Support Method for Identifying Design Requirements on Life Cycle Planning. International Journal of CAD/CAM, 13(2)

17. Rebitzer, G., T. Ekvall, R. Frischknecht, D. Hunkeler, G. Norris, T. Rydberg, W.-P. Schmidt, S. Suh, B. Weidema and D. Pennington. 2004. Life cycle assessment: Part 1: Framework, goal and scope definition, inventory analysis, and applications. Environment international, 30(5) 701-720.

18. Suesada, R., Y. Itamochi, S. Kondoh, S. Fukushige and Y. Umeda. 2007. Development of description support system for life cycle scenario. Advances in Life Cycle Engineering for Sustainable Manufacturing Businesses, Springer: 29-34.

19. Suyang, G. and J. Liu. 2010. Life Cycle Assessment on Autoliv's Electronic Control Unit. Chalmers University of Technology. Göteborg, Sweden

20. Wimmer, W., R. Züst and K.-M. Lee. 2004. Ecodesign implementation: a systematic guidance on integrating environmental considerations into product development, Springer.

21. Yang, Y., J. Bae, J. Kim and S. Suh. 2012. Replacing gasoline with corn ethanol results in significant environmental problem-shifting. Environmental science \& technology, 46(7) 3671-3678. 